\title{
Staphylococcus aureus izolatlarının tiplendirilmesinde çoklu lokus değişken sayı tekrar analizi (MLVA) ve darbeli alan jel elektroforez (PFGE) yöntemlerinin karşılaştırılması
}

\author{
Sümeyra SAVAŞ1,* \\ ${ }^{1}$ Türkiye Bilimsel ve Teknolojik Araştırma Kurumu, TÜBİTAK, \\ Bilgi ve Bilişim Güvenliği, Illeri Teknolojiler Araştırma Merkezi, Kocaeli, Türkiye
}

Gelis Tarihi (Received Date): 28.04 .2020

Kabul Tarihi (Accepted Date): 09.06.2020

$\ddot{\mathbf{O} z}$

Bu çalışmada, Staphylococcus aureus (S. aureus) bakterisi için, çoklu lokus değişken sayı tekrar analizi (MLVA) yönteminin, altın standart olarak bilinen moleküler tiplendirme yöntemi darbeli alan jel elektroforezi (PFGE) ile aylrt edebilme performansı araştırıldı. S. aureus için PFGE yönteminden elde edilen sonuçların MLVA yöntemi ile ne oranda sağlanabileceğ i belirlenmeye çalışlldı. Bu sayede rutin kullanımlarda zorlu bir yöntem olan PFGE yönteminin, daha kolay ve düşük maliyetli bir yöntem olan MLVA ile rutin de yer değiştirmesinin olanağı araştırıldd.

MLVA yöntemi hızl bir DNA izolasyon yöntemi sonrası, sdrCDE, clfA, clfB, sspA ve spa lokusları için polimeraz zincir reaksiyonu (PCR) yöntemi kullanilarak gerçekleştirildi. PFGE yöntemi ise SmaI enzimi kullanılarak elde edilen genomik DNA fragmanlart ile gerçekleştirildi. Bantlama modeli, hem görsel olarak hem de Bionumerics yazllımı ile analiz edildi. PFGE ile izolatlar 2 küme ve 16 alt tipe ayrllırken, MLVA ile aynı izolatlar, küme oluşturmaksızın 31 alt tipe ayrıldı. PCR temelli bu yöntem ile, PFGE yöntemi ile ayırt edilemeyen alt tiplerin ayırt edilebildiği görüldü. Bu sebep ile MLVA yönteminin aynı PFGE paternleri ile ilgisiz suşları daha iyi tanımlamak veya ilişkili izolatların yakın genetik kompozisyonunu doğrulamak için yüksek epidemiyolojik çözünürlüğe sahip, alternatif, verimli moleküler tipleme yöntemi olarak kullanılabileceği sonucuna varıldı.

Anahtar kelimeler: Çoklu lokus değişken sayı tekrar analizi (MLVA), darbeli alan jel elektroforezi (PFGE), ayırım gücü, moleküler tiplendirme, Staphylococcus aureus.

\footnotetext{
*Sümeyra SAVAŞ, sumeyra.savas@tubitak.gov.tr, https://orcid.org/0000-0001-5057-9178
} 


\title{
Comparison of multiple locus variable number of tandem repeat analysis (MLVA) and pulsed-field gel electrophoresis methods for typing Staphylococcus aureus isolates
}

\begin{abstract}
In this study, the performance of multi locus variable number tandem repeat analysis (MLVA) method to distinguish pulsed-field gel electrophoresis (PFGE) types, known as the gold standard, for Staphylococcus aureus ( $S$. aureus). It was tried to determine to what extent the results obtained from PFGE method for $S$. aureus can be obtained with MLVA method. In this way, the possibility of displacement of PFGE method, which is a challenging method in routine use, with MLVA, which is an easier and low cost method has been investigated.

MLVA method was performed using a polymerase chain reaction (PCR) method for sdrCDE, clfA, clfB, sspA and spa after a rapid DNA isolation method. The PFGE method was performed with genomic DNA fragments obtained using the SmaI enzyme. The banding model was analyzed both visually and with the Bionumerics software. While isolates were divided into 2 clusters and 16 subtypes with PFGE, the same izolates were divided into 31 subtypes without forming a cluster with MLVA method. With this PCR-based method, it was seen that the strains indistinguishable by PFGE method could be distinguished. Therefore, it was concluded thet MLVA can be used as an alternative, efficient molecular typing method with high epidemiological resolution to beter identify strains unrelated to the same PFGE patterns or to verify the close genetic composition of related isolates.
\end{abstract}

Keywords: Multiple-locus variable-number tandem-repeat analysis (MLVA), Pulsedfield gel electrophoresis (PFGE), discrimination power, molecular typing, Staphylococcus aureus.

\section{Giriş}

Staphylococcus aureus (S.aureus), sürülerde görülen en yıkıcı hastalıklardan birisi olan sığır mastitis hastalığına sebep olan birkaç farklı bakteriden biri olup [1], metisilin dirençli S. aureus (MRSA) başta olmak üzere, bu bakteri türü, insanlarda artış gösteren toplum kaynaklı enfeksiyonlardan sorumlu, önemli bir bakteriyel patojendir [2]. Bakteriyemi, pnömoni, endokardit ve derin apse oluşumu gibi çeşitli klinik belirtileri vardır. Metisilin dirençli S. aureus özellikle hastanelerde önemli bir klinik sorun oluşturmaktadır. Dünya çapında MRSA enfeksiyon sayısı giderek artmakta olup, bu endişe verici bir durum almıştır [3-5]. Bu sebep ile $S$. aureus enfeksiyonlarını kontrol etmek, populasyonun durumunu anlamak, alınan kontrol önlemlerine ilişkin kararları belirlemek ve toplum içerisinde yayılımı azaltarak, halk sağlığına faydalı olabilmek için $S$. aureus izolatlarının karakterizasyonu ve birbirileri arasındaki ayırımın hızlı yapılabilmesi oldukça önemlidir $[3,6,7]$.

Patojenin dünya çapında yayılımı göz önüne alındığında, çiftliklerden topluma bulaşma süreci hakkında ve yine hastaneler içinde hızlı dağılıma geniş çaplı bir epidemiyolojik 
çalışma ile cevap bulabilmek için, iyi ayırım gücüne sahip, hızlı ve kolay uygulanabilir moleküler tipleme yöntemlerinin bu patojen için belirlenmesi oldukça önemlidir [8].

Bir tiplendirme yöntemi hakkında karar verilirken, yöntemin değerlendirme aşamasında kullanılan kriterler, tekrarlanabilirlik, ayırım gücü, uygulama ve yorumlama kolaylığı oldukça önemlidir [9,10]. Moleküler tekniklerin kullanılmaya başlamasına kadar, $S$. aureus için bilinen en iyi tiplendirme metodu faj tiplendirme metoduydu [11]. Moleküler tiplendirme yöntemleri ile birlikte, S. aureus izolatlarının tiplendirilmesinde kullanılan yöntemlerden ribotipleme, amplifiye edilmiş fragman uzunluğu polimorfizmi, ssCmec tiplemesi yöntemleri bunlardan birkaçı olup [12, 13, 14] $S$. aureus izolatlarının ayırımında en yaygın olarak kullanılan yöntemler altın standart olarak bilinen darbeli alan jel elektroforez yöntemi (PFGE), çok bölgeli dizileme (MLST) ve spa dizileme yöntemleridir. PFGE yöntemi, SmaI restriksiyon enzimi ile tüm genomik DNA'nın fragmanlara ayrıldıktan sonra, özel bir agaroz jelde ayrılması esasına dayanır. MLST yöntemi ise, 7 "housekeeping" genin DNA dizi analizine dayanan laboratuarlar arası karşılaştırmalar için uygun bir tiplendirme yöntemidir. Buna rağmen, PFGE yöntemi bant boyutlarında belirsizlikler meydana gelebilme ihtimali, uzun süre alması ve emek yoğun bir yöntem olması, MLST ise, emek yoğun ve pahalı bir yöntem olması gibi sebeplerden ötürü, çoğu laboratuarda kolayca uygulanamamaktadır. Son yıllarda kullanılmaya başlayan çoklu bölge değişken tekrar analizi (MLVA) tiplendirme yöntemi, çeşitli patojenlerde kullanılmış ve başarı sağlamış bir tiplendirme yöntemidir [3, 15, 16, 17]. Belirli bir lokusta, kısa tekrar dizilerinin sayısındaki değişkenlik farklı DNA profillerini ayırarak epidemiyolojik çalışmalara fayda sağlamaktadır. Bu teknik polimeraz zincir reaksiyonu (PCR) temelli bir teknik olup, uygulama kolaylığg, zaman kazandırması ve maliyet açısından avantaj sağlamaktadır. $S$. aureus için MLVA tiplendirme yöntemi ile ilgili var olan çalışma sayısı sınırlı olup [2, 3, 6, 8, 19] bu çalışma da $S$. aureus izolatları için altın standart olarak kullanılan PFGE yöntemi ile MLVA yöntemi karşılaştırılmış, MLVA yönteminin başarı ve kullanılabilirliği araştırılmıştır.

\section{Deneysel çalışmalar}

\subsection{Bakteri izolatlart}

30 adet $S$. aureus izolatı Ankara Numune Hastanesi Mikrobiyoloji Laboratuarından temin edildi. Geçmiş zamanlarda izole edilen ve $-80^{\circ} \mathrm{C}$ de saklanan insan kaynaklı bakteri örnekleri TSA besiyerinde aktif hale getirilmiştir.

2.2. DNA izolasyonu: DNA izolasyonu için aktif hale getirilen izolatlar, nutrient broth sıvı besiyerine ekilerek $37^{\circ} \mathrm{C}$ 'de 18 saat inkübasyona bırakıldı. DNA izolasyonu için örnekler 14000 rpm'de 10 dakika santrifüj edildi. Üzerine 250 ult TE tampon (pH:8) eklendi. Üzerine $2 \mathrm{mg} / \mathrm{ml}$ konsantrasyonda lizostafinden $15 \mathrm{ul}$ eklendi. $37^{\circ} \mathrm{C}$ 'de 1 saat inkübasyondan sonra, DNA easyBlood\&tissue kit (Qiagen), önerileri doğrultusunda DNA ekstraksiyonu yapıldı ve ürün DNA ekstraktı olarak kullanıldı [18].

MLVA moleküler tiplendirme: Yöntemin uygulamasında multipleks PCR karışımı hazırlandı. MLVA yönteminde farklı genotipik izolatları ayırmak amacıyla Sebat ve arkadaşlarının protokolünden yararlanıldı [7, 20]. Karışımda 10 ul 2 X PCR tampona, $2.5 \mathrm{U} / \mu 1$ Taq DNA polimeraz (Fermantas), $1.5 \mathrm{mM} \mathrm{MgCl2,} 200 \mathrm{uM}$ dntp, 0,5 uM SspA, $1 \mu \mathrm{M}$ ClfA, $1 \mu \mathrm{M}$ ClfB, 0,5 uM spA, 1,5 uM sdrCDE ve $1 \mu \mathrm{l} 50$ ng DNA eklendi ve 
toplam hacim $20 \mu \mathrm{l}$ ' ye tamamlandı. PCR döngüleri, $94^{\circ} \mathrm{C}^{\prime} \mathrm{de} 5$ dakika başlangıç denatürasyonu, 25 döngü, $94^{\circ} \mathrm{C}^{\prime}$ de 30 saniye, $55^{\circ} \mathrm{C}$ 'de 30 saniye, $72^{\circ} \mathrm{C}^{\prime}$ de 1 dakika ve $72^{\circ} \mathrm{C}$ 'de 5 dakika son uzama olacak şekilde tamamland1 [7]. Elde edilen ürünler $\% 2$ 'lik agaroz jelde yürütülüp, görüntülendi. Amplikonlar Beckman-Coulter CEQ 8000 dizileme cihazında kapiller jel elektroforezi ile analiz edildi. Fragman analizi, PeakScanner yazılımı kullanılarak yapıldı ve Bionumerics (Applied Math, Belçika) 6.0.2 versiyonlu program MLVA eklentisine kaydedilerek dendogram oluşturuldu.

PFGE moleküler tiplendirme: Çalışmada Mulvey ve arkadaşlarının optimize ettiği PFGE protokolü kullanıldı [21]. Genomik DNA $30 \mathrm{U} / \mu 1 \mathrm{SmaI}$ enzimi ile fragmanlara ayrıldı ve \%1'lik agaroz jelde 0,5X Tris-borat-Edta (Sigma) tampon kullanılarak, CHEF-DR II (Biorad), sisteminde 24 saat $15^{\circ} \mathrm{C}$ 'de yürütüldü. Sistem $6 \mathrm{~V} / \mathrm{cm}$ akım, 5,3 sn başlangıç ve 40 sn bitiş zamanları olacak şekilde ayarlandı. Küme analizi, UPGMA yöntemi ile \%1 optimizasyon ve \%1.5 tolerans kullanılarak Dice benzerlik katsayısı ile Bionumerics (Applied Math, Belçika) 6.0.2 versiyonlu program ile gerçekleştirildi. Suşlar Tenover ve arkadaşlarının [22] kriterleri göz önüne alınarak, ayırt edilemez, farklı ve yakın ilişkili olarak kategorize edildi.

\section{Sonuçlar ve tartışma}

Tamamen birbirinden bağımsız farklı zamanlarda farklı $-80^{\circ} \mathrm{C}$ 'de saklanmış $S$. aureus örneklerinde 2 moleküler tiplendirme yönteminin karşılaştırılması yapıldı. Her iki yöntem ile de S.aureus izolatlarının tamamı tiplendirilmiştir. MLVA için 5 değişken numaralı ardışık tekrar kullanıldı. MLVA datalarına ait cluster analizi şekil 1 (B)' de gösterilmiştir. Görsel inceleme ile farklı tipler olarak sınıflandırılan izolatlar Bionumerics programı ile gruplandırılmıştır. Çalışma da tek allele göre farklılık gösteren izolatlar dendogramda da görüldüğü üzere, farklı tip olarak kabul edilmiştir. MLVA dendogramında kümeleşme görülmeyip, her izolatın A-Q2 arasında isimlendirilen 31 farklı moleküler tiplere ait olduğu saptandı.

PFGE analizi sonunda 2 küme, 16 pulsotip elde edilmiştir. Kümelerden biri pulsotip A olup 3 izolat, diğeri pulsotip $\mathrm{K}$ olup 2 izolat barındırmaktadır. Ancak Tenover kriterlerinde ki bant farklılıkları göz önüne alınarak, dendogramda \%90-95 arası benzerlik grubuna giren pulsotipler birbiriyle ayırtedilemez olarak kabul edilmiştir. \%90-85 aralığındakiler yakın ilişkili, \%85'in altında benzerlik gösterenler ise farklı pulsotip grubuna ilave edilmiştir. Buna göre, pulsotip A ve B, pulsotip E, F, G ve pulsotip K, L, M, N ve O izolatları da kendi içlerinde birbirleri ile yakın ilişkili olarak gruplandırılmıştır. PFGE datalarına ait cluster analizi Şekil 1 (A)’ da gösterilmişstir. 


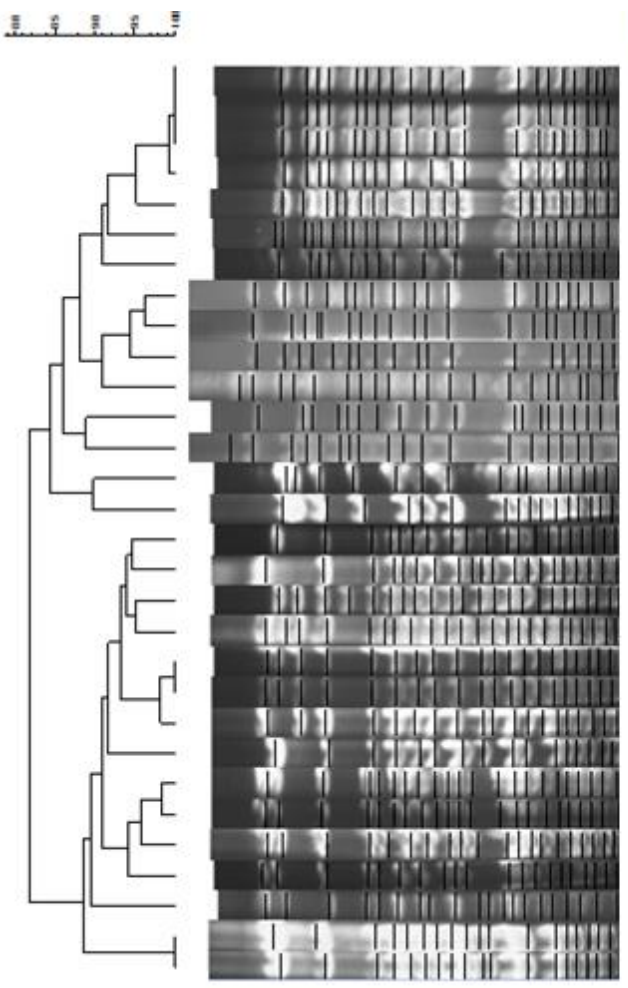

\begin{tabular}{|c|c|}
\hline Örnekno & PFGE Tipi \\
\hline ST 26 & A \\
\hline ST 7 & A \\
\hline ST 14 & A \\
\hline ST 21 & A \\
\hline ST 1 & $B$ \\
\hline ST 11 & C \\
\hline ST 20 & D \\
\hline ST 30 & E \\
\hline ST 27 & E \\
\hline ST 10 & $\mathrm{~F}$ \\
\hline ST 22 & G \\
\hline ST 18 & $\mathrm{H}$ \\
\hline ST 3 & 1 \\
\hline ST 24 & i \\
\hline ST 15 & 」 \\
\hline ST 17 & K \\
\hline ST 6 & K \\
\hline ST 25 & $K$ \\
\hline ST 13 & K \\
\hline ST 5 & K \\
\hline ST 29 & K \\
\hline ST 2 & K \\
\hline ST 16 & L \\
\hline ST 8 & $M$ \\
\hline ST 12 & M \\
\hline ST 23 & $M$ \\
\hline ST 9 & $\mathrm{M}$ \\
\hline ST 28 & $\mathrm{~N}$ \\
\hline ST 19 & 0 \\
\hline ST 4 & 0 \\
\hline
\end{tabular}

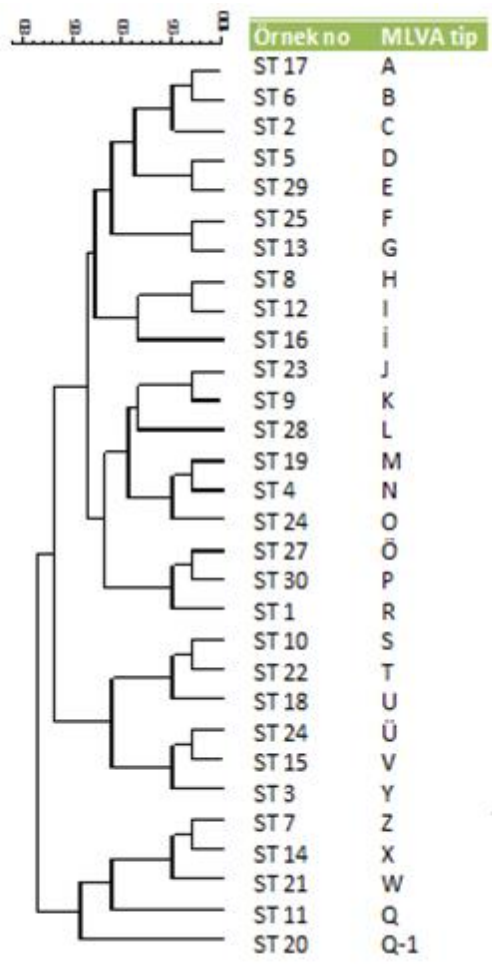

Şekil 1. (A): SmaI resktiksiyon endonükleaz enzimi, UPGMA algoritması ve Bionumerics 6.01 sürüm analiz programı kullanılarak oluşturulan $S$. aureus izolatlarına ait PFGE dendogramı. (B): Bionumerics 6.01 sürüm analiz programı kullanılarak elde edilen MLVA sonuçlarının dendogramı.

PFGE analizi ile aynı grupta ve birbiri ile ilişkili ve yakın ilişkili görülen örneklerin tek allelde ki tekrar sayısından kaynaklı farklılığa bağlı olarak, MLVA yönteminde birbiri ile ilişkisiz olduğu görülmüştür. Yapılan çalışma sonucunda, PFGE yöntemine nazaran MLVA yönteminin, $S$. aureus izolatları için, daha az zaman alan ve ayırım gücü yüksek bir yöntem olduğunu söylemek mümkündür.

Bakterilerin tiplendirilmesinde kullanılan altın standart yöntem PFGE yöntemi olup, son zamanlarda kullanılan yaygın tiplendirme yöntemlerinden birisi de MLVA tekniğidir. MLVA yöntemi hızı, kullanımı kolay, yüksek verimlilikte, nisbeten düşük maliyetli olması ve çok farklı ekipman ve reaktife ihtiyaç duymaması ile büyük avantaj sağlamaktadır. PFGE yöntemi ise, ayırım gücü yüksek olmasına rağmen, düşük taşınabilirlik ve laboratuarlar arası karşılaştırmalara uygun olmaması gibi dezavantajlara sahiptir [3].

Farklı mikroorganizmalar da PFGE ve MLVA yöntemlerinin karşılaştırıldığı çeşitli çalışmalar mevcutdur. Kjedsen ve arkadaşları Salmonella enterica'nın farklı serotiplerine MLVA ve PFGE yöntemlerini uygulamış ve S. kentucky'nin moleküler tiplendirmesinde PFGE yönteminin MLVA yöntemine göre ayırım gücünün fazla, ancak $S$. hadar için ise, tam tersi MLVA yönteminin PFGE yöntemine göre ayırım gücünün fazla olduğunu bildirmişlerdir [23]. Farklı çalışmalarda $S$. enteritidis ve $S$. dublin serotiplerinde MLVA yönteminin ayırım gücünün PFGE yöntemine göre daha baskın olduğu belirtilmiştir [24,25]. Enterokoklar için yapılan farklı bir çalışma da PFGE yönteminin ayırım gücünün MLVA yöntemine göre daha başarılı olduğu 
sonucuna varılmıştır [26]. S. aureus için her iki yöntemin karşılaştırıldığı çeşitli çalışmalar mevcut olup, farklı sonuçlara ulaşan araştırmalar mevcutdur. Malachowa ve arkadaşları yaptıkları çalışma da $S$. aureus'un tiplendirmesinde her iki yöntemin de başarı oranlarının benzer olduğunu belirtmişlerdir [2]. Tenover ve arkadaşları MLVA yönteminin PFGE tiplerini tahmin etmek amaçlı kullanılabileceğini vurgulamıştır [7]. Moser ve arkadaşları ise, MLVA metodunun özdeş PFGE paternlerine sahip ilgisiz suşları tanımlamak veya benzer izolatların yakın genetik kompozisyonunu doğrulamak için kullanılabileceğini belirtmiştir [19]. Rasschaert ve arkadaşları PFGE'nin ayırım gücünün MLVA yönteminden daha iyi olduğunu belirtmiştir [8]. Song ve arkadaşları $S$. aureus bakterisini tiplendirmek için yine her iki yöntemi de kullanmıştır. PFGE ile 28 alttip, MLVA yöntemi ile ise 29 alttip tespit etmişler, ayrıca bazı suşlar için PFGE yönteminin yetersiz kaldığını belirtmişlerdir [27].

Yapmış olduğumuz çalışma da, 30 adet farklı zamanlarda stoklanmış, birbiri ile ilişkisiz örneklere her iki yöntem de uygulanmış ve 5 farklı lokusta, S. aureus için MLVA yönteminin ayırım gücü yüksek, kullanılabilir bir tiplendirme yöntemi olduğu sonucuna varılmıştır. Buna bağlı olarak, kullanım kolaylığı, maliyetinin düşük olması gibi avantajlarına bağlı olarak, hastane içi ve hastaneler arası bulaşlarda MLVA yönteminin başarılı sonuç vereceği düşünülmektedir. Ancak örnek sayılarının çoğaltılarak, $S$.

aureus için, tiplendirme yöntemlerinin karşılaştırılması üzerine çalışmaların çoğaltılması gerektiği düşünülmektedir.

\section{Teșekkür}

Çalışma da kullanılan örneklerin teminindeki desteklerinden ötürü Doç. Dr. Gülşen Hazırolan'a ve analizlerde ki desteğinden ötürü Doç. Dr. Alper Karagöz'e teşekkürlerimi sunarım.

\section{Kaynaklar}

[1] Ruegg, P.L., A 100-year review: mastitis detection, management, and prevention, Journal of Dairy Science, 100, 10381-97, (2017).

[2] Malachowa, N., Sabat, A., Gniadkowski, M., Krzyszton-Russjan, J., Empel, J., Miedzobrodzki, J., Kosowska-Shick, K., Appelbaum, P.C., Hryniewicz, W., Comparison of multiple-locus variable-number tandem-repeat analysis with pulsed-field gel electrophoresis, spa typing and multilocus sequence typing for clonal characterization of Staphylococcus aureus isolates, Journal of Clinical Microbiology, 43, 7, 3095-3100, (2005).

[3] Schouls, L.M., Spalburg, E.C., Luit, M., Huijsdens, W., Pluister, G.N., SantenVerheuvel, M.G., Heide, H.G.J., Grundmann, H., Heck, M.E.O.C., Neeling, A.J. Multiple- locus variable number tandem repeat analysis of Staphylococcus Aureus: Comparison with pulsed-field gel electrophoresis and spa-typing, Plos one, 4, 4, e5082, (2009).

[4] de Neeling, A.J., van den Broek, M.J., Spalburg, E.C., van Santen-Verheuvel, M.G., Dam-Deisz, W.D., Boshuizen, H.C., van de Giessen, A.W., van Duijkeren, E., Huigsdens, X.W., High prevalence of methicillin resistant Staphylococcus aureus in pigs, Veterinary Microbiology, 122, 366-372, (2007).

[5] de Neeling, A.J., van Leeuwen, W.J., Schouls, L.M., Schot, C.S., van VeenRutgers, A., Beunders, A.J., Buiting, A.G., Hol, C., Ligtvoet, E.E., Petit, P.L., 
Sabbe, L.J., van Griethysen, A.J., van Embden, J.D., Resistance of staphylococci in The Netherlands: surveillance by an electronic network during 1989-1995, Journal of Antimicrobial Chemotherapy, 41, 93-101, (1998).

[6] Holmes, A., Edward, G.F., Girvan, E.K., Hannant, W., Danial, J., Fitzgerald, J.R., Templeton, K.E., Multilocus variable- number tandem-repeat methods and pulsed field gel electrophoresis for differentiating highly clonal methicillinresistant Staphylococcus aureus isolates, Journal of Clinical Microbiology, 48, 10, 3600-3607, (2010).

[7] Tenover, F.C., Vaughn, R.R., McDaugal, L.K., Fosheim, G.E., McGowan J.E., Multiple-locus variable- number tandem- repeat assay analysis of meticillinresistant Staphylococcus aureus strains, Journal of Clinical Microbiology, 45, 7, 2215-2219, (2007).

[8] Rasschaert, G., Vanderhaeghen, W., Dewaele, I., Janez, N., Huijsdens, X., Butaye, P., Heyndrickx, M., Comparison of fingerprinting methods for typing methicillin-resistant Staphylococcus aureus sequence type 398, Journal of Clinical Microbiology, 47, 10, 3313-3322, (2009).

[9] Sener, K., Saraclı, M.A., Açıkel, C.H., Doganc1, L. Türkiye Klinikleri Mikrobiyoloji Enfeksiyon, 3, 1-6, (2004).

[10] Arbeit, R.D., Laboratory procedures for epidemiologic analysis of microorganisms. In: Murray P.R., Baron E.J., Pfaller M.A., Tenover F.C., Yolken R.H. eds. Manual of Clinical Microbiology, 7th ed. Washington DC: ASM Pres, 116-37, (1999).

[11] Francois, P., Huyghe, A.,. Charbonnier, Y., Bento, M., Herzig, S., Topopski, I., Fleury, B., Lew, D., Vaudaux, P., Harbarth, S., van Leeuwen, W., van Belkum, A.,. Blanc, D.S., Pittet, D., Schrenzel, J., Use of an automated multiple-locus, variable-number tandem repeat-based method for rapid and high-throughput genotyping of Staphylococcus aureus isolates, Journal of Clinical Microbiology, 43, 3346-3355, (2005).

[12] Luczak-Kadlubowska, A., Sabat, A., Tambic-Andrasevic, A., Payerl-Pal, M., Krzyszton-Russjan, J.,. Hryniewicz, W., Usefulness of multiple-locus VNTR fingerprinting in detection of clonality of community- and hospital acquired Staphylococcus aureus isolates, Antonie van Leeuwenhoek, 94, 543- 553, (2008).

[13] Malachowa, N., Sabat, A., Gniadkowski, M., Krzyszton-Russjan, J., Empel, J., Miedzobrodzki, J., Kosowska-Shick, K., Appelbaum, P. C., Hryniewicz, W., Comparison of multiple-locus variable-number tandem-repeat analysis with pulsed-field gel electrophoresis, spa typing, and multilocus sequence typing for clonal characterization of Staphylococcus aureus isolates, Journal of Clinical Microbiology, 43, 3095-3100, (2005).

[14] Milheirico,C., Oliveira, D.C., Lencastre, H., Multiplex PCR strategy for subtyping the staphylococcal cassette chromosome mec type IV in methicillinresistant Staphylococcus aureus: 'SCCmec IV multiplex', Journal of Antimicrobial Chemotherapy, 60, 42-48, (2007).

[15] Farlow, J., Smith, K.L., Wong, J., Abrams, M., Lytle, M., Keim, P., Francisella tularensis strain typing using multiple-locus, variable-number tandem repeat analysis, Journal of Clinical Microbiology, 39, 3186-3192, (2001).

[16] Pourcel, C., Vidgop, Y., Ramisse, F., Vergnaud, G., Tram, C., Characterization of a tandem repeat polymorphism in Legionella pneumophila and its use for genotyping, Journal of Clinical Microbiology, 41, 1819-1826, (2003). 
[17] Schouls, L.M., van der Heide, H.G., Vauterin, L., Vauterin, P., Mooi, F.R. Multiple-locus variable-number tandem repeat analysis of Dutch Bordetella pertussis strains reveals rapid genetic changes with clonal expansion during the late 1990s, Journal of Bacteriology, 186, 5496-5505, (2004)

[18] Ausubel, F.M., Kingston, R.E., Brent, R., Moore, D.D., Seidman, J.G., Smith, J.A. and Struhl, K. Current protocols in molecular biology. Greene Publishing Associates \& Wiley Interscience, New York (1991).

[19] Moser, S.A., Box, M.J., Patel, M., Amaya, M., Schelonka, R., Waites, K.B., Multiple-locus variable number tandem- repeat analysis of methicillin-resistant Staphylococcus aureus discriminates within USA pulsed-field gel electrophoresis, Journal of Hospital Infection, 71, 4, 333-339, (2009).

[20] Sabat, A., Krzyszton-Russjan, J., Strzalka, W., Filipek, R., Kosowska, K., Hryniewicz, W., Travis, J., Potempa, J., New method for typing Staphylococcus aureus strains: multiple-locus variable-number tandem repeat analysis of polymorphism and genetic relationships of clinical isolates, Journal of Clinical Microbiology, 41,1801-1804, (2003).

[21] Mulvey, M.R., Chui, L., Ismail, J., Louie, L., Murphy, C., Chang, N., Alfa, M., Development of a Canadian standardized protocol for subtyping methicillinresistant Staphylococcus aureus using pulsed-field gel electrophoresis, Journal of Clinical Microbiology, 39, 3481-3485, (2001).

[22] Tenover FC, Arbeit RD, Goering RV, Mickelsen PA, Murray BE, Persing DH, Swaminathan, B., Interpreting chromosomal DNA restriction patterns produced by pulsed-field gel electrophoresis: criteria for bacterial strain typing. Journal of Clinical Microbiology, 33 (9), 2233-9, (1995).

[23] Kjeldsen, M.K., Torpdahl, M., Nielsen, E.M., Development and comparison of a generic multiple-locus variable-number tandem repeat analysis with pulsed-field gel electrophoresis for typing of Salmonella enterica subsp. Enterica, Journal of Applied Microbiology, 119, 1707-1717, (2015).

[24] Boxrud, D., Pederson-Gulrud, K., Wotton, J., Medus, C., Lyszkowicz, E., Besser, J. and Bartkus, J.M., Comparison of multiple-locus variable-number tandem repeat analysis, pulsed-field gel electrophoresis, and phage typing for subtype analysis of Salmonella enterica serotype Enteritidis, Journal of Clinical Microbiology, 45, 536-543, (2007)

[25] Liebana, E., Garcia-Migura, L., Clouting, C., Cassar, C.A., Clifton-Hadley, F.A., Lindsay, E.A., Threlfall, E.J., Chappell, S.A., Davies, R.H., Investigation of the genetic diversity among isolates of Salmonella enterica serovar Dublin from animals and humans from England, Wales and Ireland, Journal of Applied Microbiology, 93, 732-744, (2002).

[26] Top, J., Banga, N.M.I., Hayer, R., Willens, R.J., Bonten, M.J.M., Hayden, M.K., Comparison of multiple-locus var,able-number tandem repeat analysis and pulsed-field gel electrophoresis in a setting of polyclonal endemicity of vancomycin-resistant Enterococcus faecium, Clinical Microbiology and Infection, 14, 363-369, (2008).

[27] Song, M., Shi, C., Xu, X., Shi, X., Molecular typing and virulence gene profiles of enterotoxin gene cluster (egc-positive Staphylococcus aureus isolates obtained from various food and clinical specimens, Foodborne Pathogen and Disease, 13, 11, (2016). 